Revista Thema

\begin{tabular}{l|l|l} 
v.16 & n.4 & 2019
\end{tabular} p.969-983
CIÊNCIAS HUMANAS

\section{O uso do seminário na formação inicial de professores da educação profissional}

\section{The use of the seminar in the initial formation of professional education teachers}

Marilandi Maria Mascarello Vieira ${ }^{1}$, Josimar de Aparecido Vieira ${ }^{2}$

\title{
RESUMO
}

Este trabalho tem por objetivo analisar o uso do seminário como atividade pedagógica e suas contribuições na formação de professores da Educação Profissional. Trata-se de pesquisa qualitativa do tipo estudo de caso, desenvolvido com 46 egressos e estudantes que frequentaram o curso de Formação Pedagógica de Docentes para a Educação Básica e Profissional do IFRS, Câmpus Sertão, no período de 2010 a 2019. Os dados foram obtidos por meio de questionário e analisados a partir das contribuições de alguns autores. O trabalho centra-se nas acepções, finalidades e etapas do seminário e suas contribuições no processo de formação inicial de professores da EP. Os dados indicam que ele possibilita desenvolver nos estudantes a autonomia, corresponsabilidade e atuação crítica e comprometida com um processo ensino-aprendizagem significativo. Pode ser considerado como importante estratégia para o desenvolvimento da aprendizagem, promovendo o rompimento das dicotomias estabelecidas pelo paradigma tradicional de educação e a aproximação entre teoria e prática numa perspectiva interdisciplinar da situação em estudo. Contribui para a formação inicial de professores inovadores, podendo ser uma boa atividade pedagógica se for devidamente planejada e desenvolvida durante as aulas.

Palavras-chave: Educação Profissional; formação de professores; seminário.

\section{ABSTRACT}

This paper aims to analyze the use of the seminar as a pedagogical activity and its contributions in the formation of teachers of Professional Education. This is a qualitative research of the case study type, developed with 46 graduates and students who attended the IFRS, Câmpus Sertão Pedagogical Teacher Training course, from 2010 to 2019. Data were obtained through a questionnaire and analyzed from contributions of several authors. The work focuses on the meanings, purposes and stages of the seminar and their contributions to the initial teacher education process of PE. The data indicate that it enables students to develop autonomy, co-responsibility and critical performance and is committed to a meaningful teaching-learning process. It can be considered as an important strategy for the development of learning, promoting the breaking of the dichotomies established by the traditional paradigm of education and the approximation between theory and practice in an interdisciplinary

\footnotetext{
${ }^{1}$ Instituto Federal de Educação, Ciência e Tecnologia do Rio Grande do Sul - IFRS, Câmpus Sertão/RS Brasil. E-mail: marilandi.vieira@sertao.ifrs.edu.br

2 Idem. E-mail: josimar.vieira@sertao.ifrs.edu.br
} 
perspective of the situation under study. It contributes to the initial formation of innovative teachers and can be a good pedagogical activity if properly planned and developed during the classes.

Keywords: Professional education; teacher formation; seminar.

\section{INTRODUÇÃO}

Dominar uma área do conhecimento não implica, necessariamente, ser capaz de trabalhá-la em situações de ensino. A concepção de que para ser professor da Educação Profissional (EP) basta ter competência técnica, domínio de conteúdo, titulação, formação em pesquisa e publicações científicas ou ser profissional de renome no mercado vem sendo questionada. A cultura baseada na crença de que a formação pedagógica é um requisito essencial apenas para quem atua com crianças, relegando esse aspecto a um segundo plano quando se trata da EP, vem sendo alterada. Por outro lado, muitos professores são aprovados em processos seletivos cujos editais nem sempre mencionam as habilidades pedagógicas necessárias para exercer a profissão e outros profissionais podem ser convidados a atuar na docência em caráter emergencial sem apropriar-se de conhecimentos essenciais à profissão docente.

O ingresso na docência, para muitos profissionais da EP, ocorre mediante a entrega da ementa, planos de ensino de anos anteriores, horário da unidade curricular e, às vezes, cópia do Projeto Pedagógico do Curso (PPC), o que não significa, necessariamente, atribuir-lhe o sentido almejado pelos sujeitos constantemente empenhados na sua construção. Pimenta e Anastasiou (2002, p.143), afirmam, em relação ao professor ingressante que
A partir daí, as questões de sala de aula, de aprendizagem e de ensino, de metodologia e de avaliação são de sua responsabilidade, só havendo discussões acerca do processo se este sair muito da "normalidade" pretendida. Ou seja, reforça-se aí um processo de trabalho solitário, extremamente individual e individualizado; o professor é deixado à sua própria sorte e, se for bastante prudente, evitará situações extremas nas quais fiquem patentes as falhas em seu desempenho. Nessa situação, como criar uma identidade profissional?

Com a intenção de minimizar as dificuldades decorrentes dessa forma de ingresso na $E P$, instituições de ensino, por meio de ações planejadas, empenham-se em possibilitar eventos de formação continuada que se constituem em oportunidades para refletir acerca da relevância de cultivar os diferentes saberes relacionados à docência.

Muitas instituições de ensino, atualmente, adotam assessorias pedagógicas e valorizam cursos que contribuem para que os professores criem novas metodologias como fator de qualificação do ensino e reflitam sobre o processo ensinoaprendizagem. Um dos elementos que mobilizam para essas discussões, é que, diferentemente de estudantes do passado - que aceitavam mais passivamente a relação autoritária do professor -, hoje os estudantes reclamam de tais posturas. 
Atualmente a interação e a interatividade tornaram-se as palavras da moda e Souza, Moita e Carvalho (2011, p.195) assim as distinguem:

As atividades enquanto suporte de aprendizagens significativas e do desenvolvimento de novas competências envolvem necessariamente interação e interatividade que constituem características essenciais do processo de ensino aprendizagem como um todo. A interação consiste em diálogo, troca entre os interlocutores e pode ocorrer oralmente, ou por meio de um texto escrito. Por outro lado, a interatividade envolve a possibilidade de agir, intervir sobre os programas e conteúdo, agir conscientemente, tomar partido, entre outras ações.

Verifica-se na literatura educacional a insistência nas metodologias ativas como recurso para a formação de estudantes mais autônomos e, nesse rol são citadas estratégias ou recursos recentes, como a Aprendizagem Baseada na Solução de Problemas (ABProb), Aprendizagem por meio de projetos, a sala de aula invertida, Design Thinking, ensino mediado por dispositivos móveis, dentre outros. Mas também podem ser consideradas estratégias de ensino ativas o estudo de caso, a elaboração de mapas conceituais, as linhas de tempo e também o seminário, já que, segundo Barbosa e Moura (2013, p.57), “Em princípio, todo método ou estratégia que promova o envolvimento e a participação ativa do aluno no processo de desenvolvimento do conhecimento contribui para formar ambientes ativos de aprendizagem."

Nesta direção, em se tratando do processo de formação inicial de professores da EP, a complexidade dos processos de ensino-aprendizagem tem demandado aos professores formadores um enfoque mais construtivo, favorecendo a apropriação e produção dos conhecimentos. Há necessidade de se desenvolver habilidades que ultrapassem o domínio cognitivo dos conteúdos e abarquem aspectos como a leitura, compreensão e interpretação de textos científico-tecnológicos por parte dos estudantes de curso de formação de professores para a EP, a fim de que tais habilidades os auxiliem na realização de atividades de iniciação científica e no desempenho futuro de sua atuação profissional. (SANTOS; QUEIROZ, 2007).

Dentre as atividades pedagógicas que podem contribuir para o desenvolvimento da docência está o seminário, que surge como uma possibilidade de se suscitar nos estudantes a autonomia e a corresponsabilidade e estimular a atuação crítica e comprometida com o aprender significativo. O seminário pode ser considerado como importante estratégia para o desenvolvimento da aprendizagem, uma vez que possibilita uma prática docente diferenciada, podendo tornar o ensino atraente e relevante.

No entanto, em contextos educativos, muitas vezes os seminários têm sido usados por professores que não estão dispostos a "dar aula". Para isso, dividem textos, a exemplo de capítulos de livro, e solicitam aos estudantes que os expliquem. Desenvolvido desta forma, ocorre a substituição da aula expositiva do professor pelos estudantes, que apresentam a "sua parte" e saem da sala de aula e os que permanecem, não raro, demonstram desinteresse pela atividade.

Diante dessas considerações iniciais, está constituído o teor deste trabalho em que buscou-se analisar a utilização do seminário como atividade pedagógica desenvolvida na formação inicial de professores da EP e as implicações no processo formativo. Ele 
está constituído de três seções: inicia apontando as acepções e finalidades do seminário; na segunda parte trata da aplicação dessa estratégia de ensino; na sequência apresenta o percurso metodológico de produção dos dados e esboça os resultados e discussões da pesquisa. Por fim, apresenta as considerações finais do estudo.

\section{DESENVOLVIMENTO}

\subsection{ACEPÇÕES E FINALIDADES DO SEMINÁRIO}

Anastasiou e Alves (2006, p.90) escrevem que seminário “[...] é um espaço em que as ideias devem germinar ou ser semeadas. Portanto, espaço onde um grupo discute ou debate temas colocados em discussão". Veiga (2006, p.106) complementa que o seminário, em sua amplitude, é um "[...] congresso científico, cultural ou tecnológico". $\mathrm{E}$, no sentido restrito, é entendido como técnica de ensino em que o grupo de estudo “[...] debate um ou mais temas apresentados por um ou vários alunos, sob direção do professor responsável pela disciplina ou curso."

Marconi e Lakatos (1992, p.29), por sua vez, destacam que "Seminário é uma técnica de estudo que inclui pesquisa, discussão e debate. Em geral, é empregada nos cursos de graduação e pós-graduação". Ainda no intuito de conceituação, Gessinger (2008, p.166) define essa estratégia de ensino como “[...] um procedimento didático que consiste no estudo e debate de um tema ou problema, apresentado por um ou vários alunos, sob a coordenação do professor."

No que concerne às finalidades, Veiga (2006) recomenda a realização de seminários em situações em que o professor intenciona apresentar um novo tema ou aprofundar um assunto polêmico. Estudos como os de Anastasiou e Alves (2006), Gessinger (2008) e Veiga (2006) demonstraram que eles possibilitam aos estudantes oportunidade para construírem o seu conhecimento e alcançarem a aprendizagem.

Autores que discorrem sobre os propósitos do seminário indicam que Nérici (1973) é o que o apresenta de forma mais completa:

a) ensinar pesquisando; b) revelar tendências e aptidões para a pesquisa; c) levar a dominar a metodologia científica de uma disciplina; d) conferir espírito científico; e) ensinar a utilização de instrumentos lógicos de trabalho intelectual; f) ensinar a coletar material para análise e interpretação, colocando a objetividade acima da subjetividade; g) introduzir, no estudo, interpretação e crítica de trabalhos mais avançados; h) ensinar a trabalhar em grupo e desenvolver o sentimento de comunidade intelectual entre os educandos e entre estes e os professores; i) ensinar a sistematizar fatos observados e a refletir sobre eles; j) levar a assumir atitude de honestidade e exatidão nos trabalhos efetuados; k) dominar a metodologia científica geral. (NÉRICl, 1973, p.263-64).

O seminário é visto como uma estratégia cuja finalidade é preparar o estudante para o universo da pesquisa, não servindo somente para instrumentalizá-lo quanto aos tipos de pesquisa e suas técnicas, mas para desenvolver a habilidade de leitura, discussão e debate. Pode-se assegurar que ele desenvolve no estudante a capacidade de 
pesquisar e produzir conhecimento, aprendendo assim a sistematizar informações e a trabalhar em equipe.

Segundo Anastasiou e Alves (2006, p.90), se adequadamente encaminhada, essa estratégia envolve diferentes operações de pensamento, como “[...] análise, interpretação, crítica, levantamento de hipótese, busca de suposições, obtenção de organização de dados, comparação, aplicação de fatos a novas situações."

Ao escolher esta estratégia de ensino socializado objetiva-se: compreender com profundidade um problema; analisar criteriosamente ideias de autor(es) estudado(s); levantar alternativas de solução aos problemas; incorporar o diálogo crítico, investigando as razões e implicações do contexto histórico e político. Ainda nesse sentido, Gessinger (2008, p.166) explicita que o seminário

Busca desenvolver nos alunos o espírito investigativo, a autonomia, o senso crítico, a reflexão, a cooperação, a capacidade de expressar ideias com clareza, entre outros. Nesta abordagem, o conhecimento é (re)construído pelo próprio aluno, que é visto como sujeito ativo do seu processo de aprendizagem.

Tomando como referência os conceitos transcritos, depreende-se então que essa técnica de ensino se destina ao estudo de uma temática onde os estudantes assumem o papel de protagonistas construindo conhecimentos de forma independente por meio da pesquisa e do debate, o que caracteriza a aprendizagem ativa que, segundo Barbosa e Moura (2013, p.55):

[...] ocorre quando o aluno interage com o assunto em estudo - ouvindo, falando, perguntando, discutindo, fazendo e ensinando - sendo estimulado a construir o conhecimento ao invés de recebê-lo de forma passiva do professor. Em um ambiente de aprendizagem ativa, o professor atua como orientador, supervisor, facilitador do processo de aprendizagem, e não apenas como fonte única de informação e conhecimento.

Assim, mesmo considerando que essa estratégia de ensino não se constitui em inovação na área educacional, ela preenche os requisitos para ser considerada como uma metodologia ativa. Na próxima seção serão descritos os procedimentos a serem adotados para a sua aplicação em sala de aula.

\subsection{DESENVOLVIMENTO DO SEMINÁRIO}

O seminário bem conduzido é organizado em três etapas: encaminhamento, desenvolvimento e avaliação. Na primeira etapa o desafio do professor é o de planejar adequadamente a atividade e, para isso, deve mobilizar os estudantes para o conhecimento, sensibilizando-os para a importância da temática eleita e criando expectativa positiva para que realmente se envolvam com a atividade. Para tanto, é necessário apresentar ao grupo o tema e perguntas provocativas para serem respondidas por meio da pesquisa, que poderá ser teórica, mas também agregar elementos da realidade. Andrade (1998, p.89) destaca que “[...] a pesquisa, especialmente a bibliográfica, é o primeiro passo, requisito indispensável na elaboração do seminário. A pesquisa leva à discussão do material pesquisado, mas, para que os objetivos sejam alcançados, não se pode dispensar o debate". Por isso, é 
importante indicar as fontes bibliográficas a serem consultadas, bem como as formas de registro.

Também contribui para um bom resultado da aplicação dessa estratégia de ensino deixar claras as habilidades individuais e coletivas a serem desenvolvidas - como a oralização e a síntese, por exemplo -, para que os estudantes saibam em que aspectos serão avaliados e o planejamento adequado no uso dos espaços, do tempo e equipamentos. É recomendável adverti-los de que leituras demoradas, à exemplo das feitas diretamente no caderno ou folhas, podem reforçar o conceito de seminário como atividade entediante.

Se a atividade implicar em produção de texto que será disponibilizado aos colegas da turma é importante que o professor leia anteriormente o texto produzido e proponha alterações, se necessário.

Para que a pesquisa seja feita com a profundidade necessária é imprescindível atentar para o lapso temporal entre a apresentação da tarefa e a sua execução e, para tanto, é importante definir um cronograma para a socialização dos estudos. Outra dica é destinar um período de tempo de aula para que os estudantes se encontrem, produzam as sínteses e definam a metodologia de apresentação, enfim, promovam a interação, que é o principal objetivo da aplicação dessa estratégia de ensino. Sem esses momentos eles tendem a dividir tarefas e nem o próprio grupo construirá o olhar de totalidade sobre o tema.

A segunda etapa é o desenvolvimento, ou seja, a execução do seminário. Nesse momento o papel dos expositores é apresentar ao coletivo o resultado de suas pesquisas e dos demais participantes é o de elaborar questões, solicitar esclarecimentos sobre pontos não compreendidos, estabelecer confrontos entre os temas apresentados e as situações vivenciadas, enfim, não há de se admitir a passividade do grupo, já que a interação é um requisito fundamental.

O professor, por sua vez, deve coordenar a atividade, tomando o cuidado para que a discussão não fique na superficialidade, o que de fato poderá ser frustrante para todos. Após a escuta atenta ele pode propor questionamentos para estimular o debate das ideias apresentadas, mediar com a proposição de exemplos, analogias, estabelecer relações com outros temas estudados ou situações concretas, enfim, atentar-se para fazer as "tecituras complementares", as sínteses integradoras, estimulando-os a apresentarem suas conclusões finais, pois dar a voz aos estudantes permite identificar as lacunas na compreensão de assuntos estudados, favorecendo a sua superação.

Por fim, a terceira etapa do seminário é a avaliação. É essencial que o seminário resulte em uma produção por parte dos estudantes, considerando a totalidade do estudado através dessa estratégia. Caso contrário, podemos favorecer a fragmentação do conteúdo. A avaliação da atividade pode ser realizada por meio da produção de resumos, de vídeos, de quadros comparativos ou de análise crítica do assunto.

Feitas essas considerações acerca dos elementos básicos de um seminário conceituação, finalidades e forma de aplicação - em seguida apresentamos o percurso 
metodológico da pesquisa realizada acerca do tema, seguido da apresentação dos resultados e conclusões.

\subsection{PERCURSO METODOLÓGICO}

Este estudo foi desenvolvido seguindo a abordagem qualitativa, por meio de estudo de caso que foi desenvolvido com quarenta e seis egressos e estudantes do curso de Formação Pedagógica de Docentes para a Educação Básica e Profissional do Instituto Federal de Educação, Ciência e Tecnologia do Rio Grande do Sul (IFRS), Câmpus Sertão, que frequentaram/frequentam o curso entre os anos de 2010 a 2019 totalizando dez turmas - e nele cursaram a unidade curricular Sociologia da Educação - ministrada pelo mesmo professor em todas as turmas.

A temática do referido seminário foram "Os pensadores contemporâneos contribuições para o campo educacional'", fundamentado em obras clássicas dos pensadores Pierre Lévy, Boaventura de Souza Santos, Michel Foucault, Pierre Félix Bourdieu, Zygmunt Bauman, Antonio Gramsci, Paulo Freire, Antônio Sampaio da Nóvoa, Peter McLaren, Luis Althusser, Dermeval Saviani e Edgar Morin cujo objetivo foi conhecer e analisar suas principais ideias, estabelecendo relações com o campo educacional.

A razão da escolha desta unidade curricular para a realização da pesquisa decorre do fato de que ela foi ministrada pelo mesmo professor, que repetiu a experiência de aplicação do seminário ao longo do período abrangido pela pesquisa, de modo que a amostra foi considerada representativa para os objetivos da pesquisa.

Considerando que concluem o curso de Formação Pedagógica de Docentes para a Educação Básica e Profissional na instituição pesquisada em média vinte e cinco alunos por turma, foram habilitados no lapso temporal dos dez anos abrangidos na pesquisa em torno de duzentos e cinquenta profissionais que foram convidados - por e-mail - a responder a um questionário online via google docs constituído de nove questões abertas e fechadas, que versaram sobre a utilização do seminário, enfocando principalmente os conteúdos envolvidos, habilidades requeridas, percepções, alcance de objetivos, aspectos positivos e negativos da experiência vivenciada, providências necessárias e repercussões dessa atividade pedagógica para sua formação.

Dentre o total de egressos e estudantes convidados, quarenta e seis responderam ao questionário, sendo que 65,2\% cursaram a unidade curricular nos anos de 2018 e 2019 estando, portanto, ainda frequentando o curso, e 34,7\% o fizeram entre os anos de 2010 a 2017. Os dados produzidos foram compilados, organizados em categorias e os resultados e conclusões do estudo constam na próxima seção.

\subsection{RESULTADOS E DISCUSSÕES}

\subsubsection{Organização do seminário}

Os participantes, interlocutores da pesquisa, foram convidados a responder quatro questões sobre os aspectos envolvidos na organização do seminário: em relação aos 


\section{Revista Thema}

seus objetivos, os conteúdos apresentados, os encaminhamentos necessários no planejamento e as habilidades de comunicação.

Sobre o primeiro tema a questão foi fechada, ou seja, nela constavam os objetivos e os respondentes deveriam demonstrar seu nível de concordância em relação a experiência em análise ter atingido os objetivos para a qual foi proposta. Foi respondida por 42 participantes e suas respostas constam no quadro 1.

Quadro 1 - Objetivos do seminário.

\begin{tabular}{|l|c|c|c|c|c|}
\hline \multicolumn{1}{|c|}{ Objetivos do seminário } & DT & D & NS & C & CT \\
\hline $\begin{array}{l}\text { Investigou os temas sob diferentes perspectivas, com } \\
\text { profundidade de compreensão }\end{array}$ & 1 & - & 1 & 24 & 16 \\
\hline Analisou criticamente ideias de autores estudados & - & 1 & 2 & 22 & 18 \\
\hline $\begin{array}{l}\text { Propôs alternativas para resolver questões levanta- } \\
\text { das }\end{array}$ & 1 & 1 & 10 & 22 & 9 \\
\hline Trabalhou o tema de forma cooperativa & - & 1 & 2 & 22 & 17 \\
\hline Introduziu o diálogo crítico sobre os temas & - & 1 & 2 & 21 & 19 \\
\hline
\end{tabular}

Fonte: Elaborado pelos autores.

Os resultados indicam que a quase totalidade dos pesquisados ( $C$ e $C T$ ) considera que o seminário realizado atingiu os objetivos a que se propôs. A menor incidência de respostas esteve ligada à proposição de alternativas para resolver questões levantadas. Podemos aventar que essa menor incidência de respostas está ligada ao fato de que a temática do seminário envolve mais análise de ideias do que sua aplicabilidade em situações concretas, de modo que é difícil precisar alternativas de resolução de questões.

Em relação aos conteúdos, a questão era fechada, possibilitando a marcação de apenas uma das proposições, e apresentava os aspectos que elegeram como contribuições importantes do seminário. Responderam a ela os 46 participantes e os resultados obtidos foram os seguintes:

Quadro 2 - Aspectos relevantes em relação aos conteúdos.

\begin{tabular}{|l|c|}
\hline \multicolumn{1}{|c|}{ Conteúdos - aspectos relevantes } & \% \\
\hline Domínio do conteúdo por todos os integrantes do grupo & 41,3 \\
\hline Clareza dos conceitos fundamentais relativos ao tema apresentado & 32,6 \\
\hline Seleção quantitativa e qualitativa do material a ser estudado & 15,2 \\
\hline Sequência lógica das ideias - subtemas & 6,5 \\
\hline Adequação da extensão do tema em relação ao tempo disponível & 4,3 \\
\hline \multicolumn{1}{|c|}{ TOTAL } & $\mathbf{1 0 0}$ \\
\hline
\end{tabular}

Fonte: Elaborado pelos autores.

Os dados indicam que $73,9 \%$ dos participantes - que corresponde a 34 - consideram que o seminário contribuiu para o domínio de conteúdos/conceitos (proposições 1 e 2) e esse foi o foco central de suas preocupações ao planejar o evento. Os demais participantes referiram-se a aspectos ligados à seleção, encadeamento e extensão dos temas.

O terceiro aspecto diz respeito às providências que os estudantes tiveram de tomar na fase de organização do seminário e, tratando-se de questão aberta, as 44 respostas foram analisadas e agrupadas nas categorias elencadas no quadro 3: 
Quadro 3 - Aspectos relevantes na preparação da atividade.

\begin{tabular}{|l|c|}
\hline \multicolumn{1}{|c|}{ Providências - aspectos relevantes } & \% \\
\hline Leitura para aprofundamento do tema & 41,5 \\
\hline Busca e seleção de material de estudo & 22,6 \\
\hline Planejamento da aula/elaboração de material didático & 28,3 \\
\hline Preparação de argumentos para defesa das ideias a serem apresentadas & 3,8 \\
\hline Outros & 3,8 \\
\hline \multicolumn{1}{|c|}{ TOTAL } & $\mathbf{1 0 0}$ \\
\hline
\end{tabular}

Fonte: Elaborado pelos autores.

Observa-se que o que mais demandou esforços na preparação do seminário foi a busca de fontes de pesquisa e informações e a leitura para aprofundamento do tema, o que corrobora os argumentos dos autores estudados que essa técnica de ensino contribui para o protagonismo e independência intelectual do estudante, desenvolvendo as habilidades de investigação. Segundo Barbosa e Moura (2013, p.65)

As contribuições das metodologias ativas nos permitem prever que, em vez de alunos saindo da escola com a ilusão de terem aprendido algo só porque foram expostos a conteúdos em aulas expositivas, teremos alunos que experimentaram situações de aprendizagem profundamente significativas em suas vidas. Se sentirem falta de algum tópico, saberão onde encontrá-lo e o que fazer para aprendê-lo.

Outro aspecto apontado pelos participantes da pesquisa foi a preocupação em planejar as atividades visando o desenvolvimento de habilidades de comunicação. A questão era fechada e os participantes - 46 a responderam - puderam assinalar uma única proposição e, assim, consideraram relevante planejar a tarefa nos seguintes quesitos:

Quadro 4 - Aspectos relevantes em relação a habilidades de comunicação.

\begin{tabular}{|l|c|}
\hline \multicolumn{1}{|c|}{ Comunicação - aspectos relevantes } & \% \\
\hline Uso de vocabulário adequado a turma & $42,3 \%$ \\
\hline Expressão verbal (entonação, pronúncia, ritmo e qualidade da voz) & 19,6 \\
\hline Autocontrole frente ao grupo & 17,4 \\
\hline Estabelecer empatia com o grupo & 15,2 \\
\hline Postura corporal & 6,5 \\
\hline \multicolumn{1}{|c|}{ TOTAL } & $\mathbf{1 0 0}$ \\
\hline
\end{tabular}

Fonte: Elaborado pelos autores.

Os dados indicam que o maior foco de atenção na preparação da atividade foi o cuidado com o uso de vocabulário adequado à turma, os aspectos relativos à expressão verbal adequada e o exercício de autocontrole durante o desenvolvimento da atividade. Assim, é possível concluir que essa é uma importante ferramenta didática porque proporciona o exercício da exposição, da expressão oral e desinibe os expositores e participantes, que tem espaço para expressar suas ideias.

\subsubsection{Desenvolvimento do seminário}

Em relação à fase de execução do seminário os participantes expressaram suas opiniões por meio de uma questão aberta em que se solicitou os aspectos positivos do uso dessa estratégia de ensino. Os conteúdos de suas respostas - no total foram 43 respondentes que apontaram um ou mais aspectos - foram categorizadas e constam no quadro 5: 
Quadro 5 - Aspectos positivos do seminário realizado.

\begin{tabular}{|l|c|}
\hline \multicolumn{1}{|c|}{ Aspectos positivos do seminário } & No \\
\hline $\begin{array}{l}\text { Favoreceu a interação, a ajuda mútua e o compartilhamento de saberes entre os estu- } \\
\text { dantes }\end{array}$ & 23 \\
\hline Permitiu o estudo de temas novos ou auxiliou no aprofundamento de temas relevantes. & 18 \\
\hline $\begin{array}{l}\text { Atividade desenvolvida de forma dinâmica, que proporcionou o envolvimento e a partici- } \\
\text { pação dos estudantes, estimulando a pesquisa, o debate e a análise crítica }\end{array}$ & 14 \\
\hline Estratégia que contribuiu para desenvolver habilidades docentes & 5 \\
\hline
\end{tabular}

Fonte: Elaborado pelos autores.

A atividade foi considerada positiva porque proporcionou a interação e a ajuda mútua entre os membros do grupo e o coletivo da turma, ideias que foram expressas com registros como "A possibilidade de compartilhar conhecimento com os colegas", "a interação da turma durante o seminário". Também foram marcantes os registros referentes ao compartilhamento de diferentes opiniões a respeito do tema. Ressalte-se que, advindos de cursos de formação universitária de diferentes áreas, a troca de saberes permite maior crescimento aos participantes, à medida que vão tendo oportunidade de ampliar sua concepção de mundo pela multiplicidade de pontos de vista sobre eles, conforme expressam alguns registros que apresentamos a título de exemplificação:

A diversidade de percepção sobre os temas abordados no seminário.

Companheirismo com os colegas e a heterogeneidade de ideias.

O envolvimento da turma, as discussões, o aprendizado de temas nunca antes abordados na minha formação.

Discutir as diversas percepções dos alunos sobre os temas estudados.

O estímulo à pesquisa e ao debate também foi apontado como ponto positivo dessa estratégia de ensino, que exemplificamos com alguns registros:

Um ponto positivo foi o de proporcionar a pesquisa, organização e o debate com colegas que facilitou a aprendizagem e fixação dos conteúdos.

O seminário exigiu base teórica e referência para sustentar a exposição das reflexões propostas, saindo do senso comum.

As argumentações e exposições feitas pelos participantes contribuiu para o bom andamento do seminário.

Os registros nos levam a considerar o seminário como uma oportunidade de aprendizagem significativa que, segundo Gadotti (1994, p.319), “[...] é facilitada quando o aluno participa responsavelmente do seu processo. A aprendizagem autoiniciada que envolve toda a pessoa do aprendiz - seus sentimentos tanto quanto sua inteligência - é a mais durável e penetrante."

Também se procurou identificar, por meio de uma questão aberta, o que os pesquisados consideram negativo durante a execução do seminário e, das 40 respostas registradas, 11 afirmaram não ter nenhum aspecto negativo a considerar, enquanto outros 31 apontaram os aspectos categorizados no quadro 6: 
Quadro 6 - Aspectos negativos do seminário realizado.

\begin{tabular}{|l|c|}
\hline \multicolumn{1}{|c|}{ Aspectos negativos do seminário } & No \\
\hline Tempo destinado a apresentação (demasiado ou insuficiente) & 7 \\
\hline Tempo destinado a preparação da atividade foi insuficiente & 4 \\
\hline Pouco auxílio do professor na preparação e indicação de material de pesquisa & 3 \\
\hline Falta de domínio do conteúdo por alguns colegas prejudicando o aprendizado & 3 \\
\hline Pouca participação de alguns colegas no debate das ideias apresentadas & 3 \\
\hline Baixo grau de envolvimento dos colegas no grupo na preparação da atividade & 2 \\
\hline $\begin{array}{l}\text { Apresentação pouco dinâmica (material didático, ausência de questões geradoras de } \\
\text { debate etc.) }\end{array}$ & 3 \\
\hline Tema pouco conhecido e dificuldade de compreender as ideias centrais & 2 \\
\hline Horário que não favorecia a realização da atividade (sábado à tarde) & 1 \\
\hline Intervenção do professor durante a apresentação & 1 \\
\hline Outros aspectos & 3 \\
\hline
\end{tabular}

Fonte: Elaborado pelos autores.

O tempo destinado à preparação e à apresentação foi apontado como aspecto negativo pelos participantes, sendo que, para alguns, o mesmo foi considerado insuficiente, enquanto para outros foi demasiado. Isso se explica porque as respostas representam a opinião de estudantes de dez turmas distintas e em cada uma delas a execução da tarefa pode ter comportado variação de tempo em razão da ocorrência de eventos que podem ter comprometido o andamento das atividades planejadas. Alguns registros que exemplificam essa situação constam nas transcrições a seguir:

A sequência de seminários por um logo período tornou as aulas mais cansativas. Talvez diminuindo a duração de cada apresentação ficasse mais dinâmico.

Alguns grupos excederam muito o tempo e acabaram se tornando cansativos.

Outro aspecto negativo - já indicado pelos autores como um dos riscos no uso dessa estratégia de ensino - é o despreparo do expositor e, consequentemente, o pouco aprofundamento da temática, comprometendo o aprendizado da turma, conforme expresso em dois registros:

Alguns grupos ou integrantes de grupos não aprofundaram a pesquisa sobre o tema, citando apenas conceitos básicos e perdendo a oportunidade de propor debates e reflexão mais ampla e contextualizada.

A falta de domínio de conteúdo por alguns colegas era visível. Percebeuse que não haviam se dedicado a preparação da apresentação.

Os aspectos apontados pelos participantes, de modo geral, ratificam as afirmações encontradas na literatura referente ao tema, tanto em relação às contribuições do seminário para o aprendizado e desenvolvimento de habilidades de pesquisa, de comunicação e de debate quanto aos riscos que esta técnica está sujeita se não for bem planejada e desenvolvida pelos participantes.

\subsubsection{Avaliação dos resultados obtidos com o seminário}

Os participantes foram instados a avaliar a participação no seminário apontando as contribuições dessa atividade para sua formação profissional. A questão era fechada, 


\section{Revista Thema}

de múltipla escolha e com cinco alternativas e foi respondida por 46 participantes, conforme consta no quadro a seguir:

Quadro 7 - Contribuições da participação em seminário.

\begin{tabular}{|c|c|c|c|c|c|}
\hline Contribuições do seminário & DT & $\mathbf{D}$ & NS & $\mathbf{C}$ & CT \\
\hline A atividade melhorou minha aprendizagem & - & - & 6 & 20 & 20 \\
\hline Boa oportunidade para aprender com os colegas & & 1 & 1 & 18 & 21 \\
\hline $\begin{array}{l}\text { Organizei as ideias a partir das leituras e discussões } \\
\text { com os colegas. }\end{array}$ & 1 & 2 & 1 & 20 & 17 \\
\hline Ajudou a lembrar conceitos estudados anteriormente & 3 & 1 & 9 & 17 & 12 \\
\hline $\begin{array}{l}\text { Auxiliou na organização dos conceitos tornando mais } \\
\text { fácil a compreensão do conteúdo abordado }\end{array}$ & 1 & 1 & 2 & 23 & 15 \\
\hline $\begin{array}{l}\text { Tornou mais claro o conhecimento sobre o tema estu- } \\
\text { dado }\end{array}$ & 1 & - & 2 & 25 & 13 \\
\hline
\end{tabular}

Fonte: Elaborado pelos autores.

A maior incidência de resposta refere-se à melhoria da aprendizagem, especialmente por meio da interação com os colegas (proposições 1 e 2), bem como a maior facilidade na apreensão dos conteúdos por meio de leituras e discussões.

Outra questão foi proposta com o mesmo objetivo, ou seja, identificar as contribuições do seminário, porém foi redigida de forma aberta e enfocando o trabalho docente. As respostas apontadas por 44 participantes foram categorizadas e constam no quadro 8.

Quadro 8 - Contribuições do seminário para a formação docente.

\begin{tabular}{|l|c|}
\hline \multicolumn{1}{|c|}{ Contribuições do seminário para a formação docente } & No \\
\hline $\begin{array}{l}\text { Mudança de visão sobre educação/quebra de paradigma/respeito a opiniões dife- } \\
\text { rentes }\end{array}$ & 19 \\
\hline $\begin{array}{l}\text { Desenvolvimento de habilidades docentes (pesquisa, organização da aula, preparo } \\
\text { de matéria, } \\
\text { desenvoltura na apresentação etc). }\end{array}$ & 6 \\
\hline $\begin{array}{l}\text { Contribuiu para desenvolver a autonomia, a iniciativa, a reflexão e pensamento } \\
\text { crítico }\end{array}$ & 6 \\
\hline Outras (positivas/importantes/expressiva/conhecimentos novos) & 5 \\
\hline Nenhuma/não ajudou & 2 \\
\hline
\end{tabular}

Fonte: Elaborado pelos autores.

Os dados apontam como de maior relevância a mudança de postura frente ao conhecimento e relativas a visão sobre educação, mudanças de paradigmas e respeito a diversidade de opiniões. Os depoimentos a seguir expressam as opiniões referentes à essa categoria:

Foi possível discutir e considerar diversos aspectos e pontos de vista diferentes.

Ampliou a minha visão sobre a sociedade.

Abriu alguns aspectos que não estão no meu dia a dia. Apesar de não concordar com alguns autores e alguns posicionamentos contrários às minhas convicções, tudo foi válido, pois teremos todos os tipos de alunos, com suas ideias e conceitos.

Flexibilização maior frente a opiniões contrárias sobre temas polêmicos, por vezes aproveitando o contraditório para propor reflexões mais 
aprofundadas sobre assuntos estratégicos que não possuem visibilidade, mas estão intrínsecos em atos políticos e sociais.

Ressalte-se que esse é um exercício importante para a formação do futuro professor, já que ele terá de conviver em instituições de ensino inclusivas, com estudantes oriundos de diferentes etnias e culturas, com padrões de comportamento diferenciados, o que exige conhecimento multidisciplinar. Marques (1996, p.14) nos ajuda a refletir sobre as respostas dos participantes da pesquisa quando afirma que

A educação se cumpre num diálogo de saberes, não em simples troca de informações, nem em mero assentimento acrítico a proposições alheias, mas na busca do entendimento compartilhado entre todos os que participam da mesma comunidade de vida, de trabalho, de uma comunidade discursiva de argumentação.

A segunda categoria diz respeito ao desenvolvimento de habilidades docentes como a pesquisa, o planejamento docente e a desenvoltura durante a apresentação dos temas, que foram expressas em depoimentos como:

Contribuiu muito, pois possibilitou o estudo do tema, a necessidade de organização, além da elaboração do material escrito repassado aos colegas, por fim, a apresentação do trabalho, proporcionando assim um contato com a realidade do trabalho de um professor.

Leitura, organização de material e slides, que todos podem aprender juntos, que o diálogo e a reflexão são importantes, que exemplos práticos influenciam o aprendizado bem como a memorização! Sempre em seminários há troca de saberes entre docente e docentes e com certeza contribuem para a formação! É um método muito bom para ser utilizado na construção do conhecimento!

Uma excelente experiência para expor e dialogar sobre os conteúdos, ter postura e saber falar com clareza.

Shulman (2005) faz referência a importância de o professor desenvolver as habilidades relativas à seleção de estratégias mais pertinentes para ensinar cada tópico do conteúdo em circunstâncias específicas em sala de aula, o que inclui a forma como ele interpreta o conteúdo e o transforma para facilitar a compreensão por parte do estudante, mobilizando-o para o conhecimento. Isso significa que ele precisa transformar o conteúdo da matéria em atividades e experiências para facilitar o aprendizado, o que inclui as analogias, o uso de exemplos, explicações e demonstrações daquele tópico específico do conteúdo. O exercício do seminário permite que o futuro professor exercite essas habilidades, servindo de aprendizado para o exercício profissional.

\section{CONSIDERAÇÕES FINAIS}

Seminários podem ser utilizados em diferentes situações no decorrer do processo de formação inicial de professores. Neste estudo, os estudantes planejaram e desenvolveram o seminário durante as aulas da unidade curricular Sociologia da Educação que faz parte do curso de Formação Pedagógica de Docentes para a Educação Básica e Profissional. 
Nesta unidade curricular e curso, leituras de livros e artigos científicos são práticas recorrentes no contexto acadêmico e devem ser inseridas no cotidiano dos estudantes desde os primeiros anos da vida universitária. A adoção de estratégias que facilitem a compreensão desses materiais e a aprendizagem é essencial para incentivar nos estudantes o hábito da leitura e a apreensão crítica das teorias produzidas, tão necessárias na profissão docente.

O desenvolvimento de seminário sobre "Os pensadores contemporâneos contribuições para o campo educacional' demonstrou ser estratégia apropriada para a promoção da aprendizagem. Tendo como objetivo "Conhecer criticamente pensadores contemporâneos, analisando suas principais ideias e estabelecendo relações com o campo educacional", o citado seminário tornou-se importante atividade onde os estudantes e professores compreenderam criticamente as ideias dos pensadores nele abordados.

Além disso, a realização do seminário possibilitou ao professor o acompanhamento e a avaliação da aprendizagem, bem como o auxiliou na detecção de dificuldades nos conteúdos estudados. Ao ser trabalhado em grupo, incentivou uma maior participação dos estudantes nas atividades, tornando-as mais interativas e dinâmicas, possibilitando o desenvolvimento da sua autonomia no processo ensinoaprendizagem.

As atividades em grupo facilitaram a organização do conhecimento e a aprendizagem. Os participantes da pesquisa afirmaram que se tornaram mais participativos e que a estratégia incentivou a sua autonomia na construção do conhecimento e caracterizouse como um espaço para a discussão e partilha de ideias.

O diálogo com os autores a que fizemos referência permitiu a compreensão de que o ensino desenvolvido por meio de seminários, na prática pedagógica da formação inicial de professores, além de exigir o compromisso do professor com a produção do conhecimento, oportuniza o envolvimento dos estudantes no processo, para que desempenhem o papel de protagonistas. (VEIGA, 2006).

Outro aspecto positivo a ser considerado refere-se ao diálogo entre os participantes durante o seminário, possibilitando “[...] a cooperação, o auxílio mútuo e a socialização de experiências que levam à (re) construção de um novo conhecimento, enriquecido pelo caráter de coletividade e de participação." (GRILLO, 2000, p.146).

Enfim, conclui-se que a atividade permite o desenvolvimento de habilidades como o pensamento crítico, o trabalho colaborativo e a comunicação e torna-se importante trazer à sala de aula a oportunidade de levar o estudante universitário a um crescimento mais efetivo, que lhe favoreça o desenvolvimento de habilidades profissionais.

\section{REFERÊNCIAS}

ANASTASIOU, L. G. C.; ALVES, L. P. (Org.). Processos de ensinagem na

universidade: pressupostos para as estratégias de trabalho docente em aula. 6. ed. Joinville: Univille, 2006. 
ANDRADE, M. M. A elaboração de seminários. In: ANASTASIOU, L. G. C.; ALVES, L. P. Introdução à metodologia do trabalho científico: elaboração de trabalhos na graduação. 3. ed. São Paulo: Atlas, 1998, p.109-117.

BARBOSA; E.F.; MOURA, D.G. Metodologias ativas de aprendizagem na Educação Profissional e Tecnológica. Boletim Técnico do SENAC, Rio de Janeiro, v.39, n.2, p.4867, mai./ago. 2013.

GESSINGER, M. C. Seminário. In: FREITAS, A. L.; GESSINGER, R. M.; GRILLO, M. C.; LIMA, V. M. R. (Org.). A gestão da aula universitária na PUCRS. Porto Alegre: EDIPUCRS, 2008. p.166-169.

GADOTTI, M. História das ideias pedagógicas. 2. ed. São Paulo: Ática, 1994.

GIL, A. C. Metodologia do ensino superior. 3. ed. São Paulo: Atlas, 1997.

GRILLO, M. C. O lugar da reflexão na construção do conhecimento profissional. In: MOROSINI, M. C. (Org.). Professor do Ensino Superior: identidade, docência e formação. Brasília: Instituto Nacional de Estudos e Pesquisas Educacionais, 2000.

MARCONI, M. A.; LAKATOS, E. Metodologia do trabalho científico. 4. ed. São Paulo: Atlas, 1992.

MARQUES, M.O. A aprendizagem na mediação social do aprendido e da docência. ljuí: Editora Unijuí, 1995.

NERICl, I. G. Educação e metodologia. 2. ed. Rio de Janeiro: Fundo de Cultura, 1973. PIMENTA, S.G; ANASTASIOU, L.G. Docência no Ensino Superior. São Paulo: Cortez, 2002.

SANTOS, G. R.; QUEIROZ, S. L. Leitura e interpretação de artigos científicos por alunos de graduação em química. Ciência \& Educação, Bauru, v.13, n.2, p.193-209, 2007.

SEVERINO, A. J. Metodologia do trabalho científico. São Paulo: Cortez, 2002.

SHULMAN, L.S. Conocimiento y enseñanza: fundamentos de la nueva reforma.

Profesorado, Revista de Currículum y Formación de Profesorado, v.9, n.2, Granada, España, p.1-30, 2005.

SOUSA, R. P. D.; MOITA, F. D.; CARVALHO, A. B. G. Tecnologias Digitais na Educação. Paraíba: Eduepb, 2011.

VEIGA, I. P. A. O seminário como técnica de ensino socializado. In: SOUSA, R. P. D.; MOITA, F. D.; CARVALHO, A. B. G. (Org.). Técnicas de ensino: por que não?. 4. ed. Campinas: Papirus, 2006. p.103-113. 